\title{
Configuring bariatric bodies: exploring obesity surgery beyond the hospital
}

\section{Configurando cuerpos bariátricos: explorando la cirugía más allá del hospital}

\author{
Jordi Sanz Porras \\ Faculty of Sociology (Lancaster University) \\ j.sanzporras@lancaster.ac.k
}

\begin{abstract}
Resumen
La cirugía bariàtrica deviene en muchos casos la última alternativa terapéutica para pacientes con obesidad mórbida grave. Basándose en una etnografía hospitalaria en la unidad de cirugía bariátrica, este artículo pretende explorar la configuración de los cuerpos para que la misma cirugía mantenga su status de tratamiento válido más allá del quirófano. Sin embargo, lo que en términos de restauración médica se llaman efectos colaterales, en términos de configuración corporal son nuevas relaciones semiótico-materiales que tienen en el quirófano su punto de partida. El sistema digestivo bariátrico no necesariamente encajará en el complejo de relaciones que lo sustenten tras dejar el hospital: el paciente deberá afrontar la (dis)capacidad de comer pequeñas porciones de comida y una deteriorada capacidad para absorber nutrientes.
\end{abstract}

Palabras clave: Configuración corporal; Actornetwork theory; Cirugía bariátrica

\section{Abstract}

Bariatric surgery (surgery for obesity) is, in many cases, the last resort for the clinically overweight. Drawing on ethnographic materials in a unit of morbid obesity, this article explores how "bariatric bodies" are configured so that bariatric surgery is a sustainable solution beyond the operation theatre. However, what medicine calls 'side-effects', are, in terms of body configuration, a new set of semiotic-material relationships which start, but do not end, in the operating theatre. The bariatric digestive system might not necessarily fit with the set of relations with which it has to deal on leaving the hospital: the person will have to cope with eating very little, and with being able to ingest only a very limited amount of nutrients.

Keywords: Body configuration; Actor-Network Theory; Bariatric Surgery; Obesity

\section{Introduction}

For many morbid obese patients, bariatric surgery becomes the only way to improve in their condition. These kind of extensive surgical measures are major gastrointestinal operations that (a) seal off most of the stomach to reduce the amount of food one can eat and (b) rearrange the small intestine to 
reduce the calories the bodies can absorb. Bile and pancreatic secretions, which are necessary for digestion of food, are directed away from the food.

Drawing on ethnographical fieldwork in a unit of morbid obesity, this article explores how bariatric surgery is extended beyond the hospital by creating its own 'bodies', bariatrical bodies. My argument is that bariatric surgery is not only a restorative medical procedure but at the same time a body configuration process. What in terms of medical restoration are called 'side-effects', in terms of body configuration are a new set of semiotic-material relationships which have in the operation theatre their point of departure. The procedures undertaken by this kind of invasive treatment are not reversible and after leaving the operation room the person will be embedded with the (dis)ability to eat exclusively a small amount of food and a low capacity of nutrients assimilation.

After leaving the hospital, bariatric surgery calls for a psychological preparation on the part of the patient and a fairly long period of adaptation to life with a small stomach and malabsorptive intestines. It compels patients to change their eating habits radically, and makes them very ill if they overeat. And after bariatric surgery is performed, patients remain at a lifelong risk of nutritional deficiencies. The higher the motivation of patients to lose weight, and manage the post-operative requirements of dietary modification and behavioural therapy, the more successful bariatric surgery is likely to be, in solving their obesity and weight related problems.

\section{Bariatric surgery as a treatment for morbid obesity}

Obesity is a wide-spread and life-shortening disease that can be defined as a pathologic accumulation of fat reserves described as one of the main hazards afflicting the Catalan society. Its rapidly widespread occurrence and increasing severity fit the criteria used to diagnose an epidemic.

Obesity has been for too long considered simply as a case of an unbalanced energy budget, the emphasise being placed on the food intake. The association between food intake and obesity has been established in conjunction with sinfulness, lack of control and a delight in earthly pleasures. Due to the fact that these beliefs remain alive and deeply rooted in the minds of a large section of the Catalan society, an awareness of the dangers of obesity has been awakened by major medical practitioners.

In spite of its epidemic character, no fully effective treatments are available. The strategies used to cope with obesity have relied mainly on the limitation of energy intake and/or energy expenditure. The most frequent method to limit energy is the administration of hypocaloric diets. The inhibition of the absorption of nutrients through specific digestive enzymes inhibitors has been also used. The effectiveness of this dietary regime is limited when facing morbid obesity although it has consolidated as the most extended therapeutic choice to treat overweigh. Secondly, the corollary assumption that obesity is a direct consequence of excessive food intake is that the obese remain as such because they lack of willpower to distance themselves from food: if they are obese is because they ingest more energy than needed and the rest becomes fat. Psychological conditioning has been used to maintain the obese far from food as much as possible, but results have been very poor. The focus on changing daily eating habits, removal of stressful influences and the morbid fear of becoming fat may help to monitor, but not to reduce, obesity. Some individual studies show how such approach can produce good initial weight loss and some degree of weight maintenance (Perri at al, 2000). Long term studies (Wilson, 1995; NHS Centre reviews and Dissemination, 1997; Odgen, 2003) contradict this 
achievement: patients who lost weight initially regain it after three years and even may exacerbate problems with eating control and result in weight cycling and overeating.

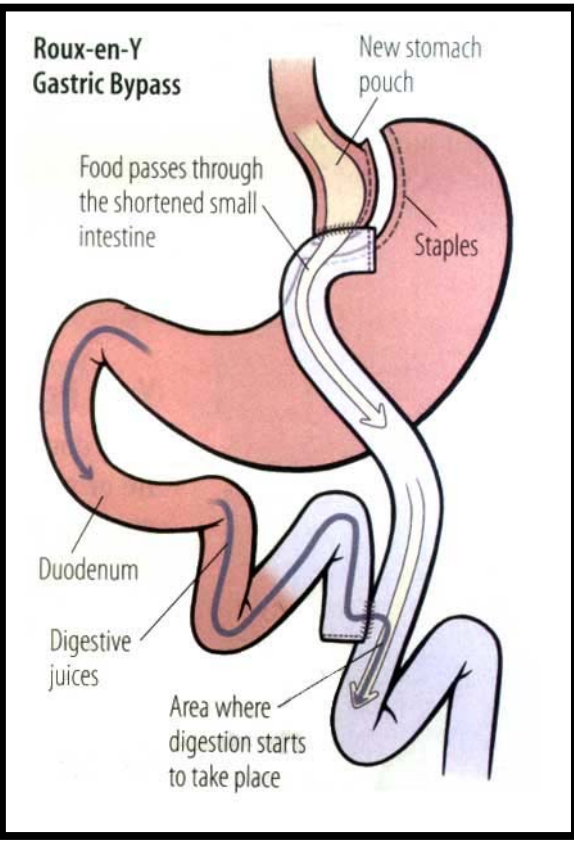

Surgery is the option used to produce a mechanical barrier to food intake and cope with the patients on which other treatments have failed. Bariatric surgery is constituted as the most common and extended way considered to effectively treating morbid obesity in Catalonia (although it is not appropriate to treat overweight people). But for many morbid obese, this kind of extensive surgery becomes the only way to improve in their condition. Generally speaking, bariatric surgical procedures are major gastrointestinal operations that (a) seal off most of the stomach to reduce the amount of food one can eat (only a limited amount of food can be eaten prior to getting full), and (b) rearrange the small intestine to reduce the calories the bodies can absorb. Bile and pancreatic secretions, which are necessary for digestion of food, are directed away from the food. These secretions reach the food several centimetres down the length of the small bowel, thus delaying and causing incomplete digestion and absorption of the food.

Two of the most common types of surgery are Vertical Gastroplasty (VG) and Gastric Bypass. In VG, a small pouch is created at the top of the stomach and a small ring is placed at the bottom of the pouch, which acts as an artificial sphincter. This technique results in an average weight loss of $50 \%$ of excess body weight (Galibert \& Kral, 2001). A more drastic procedure, Roux-n-y or Gastric Bypass, involves the complete partition of the stomach, creating a small pouch that is connected to the small bowel (Galibert \& Kral, 2001). An average of $63 \%$ of excess body weight is lost as a result of Gastric bypass.

A wide number of studies have been dedicated to demonstrate the effectiveness of the surgery in relation to long term weight lost and also the reduction in the risk factors for comorbidities associated with morbid obesity. For example, Jurgen Torgerson and Lars Sjostrom (2001) explored a 1000 matched pairs of patients, who received either surgery or conventional treatment for their obesity. Their results showed an average of $28 \mathrm{kgs}$ in the surgical group after two years match up to only 0.5 $\mathrm{kgs}$ in the conventional group. A second example is the work of Nicholas Cristou et alt. (2004) which gave evidence about the reduction mean percent excess weight loss $(67.1 \%, P<0.001)$ in patients who undergone bariatric surgery. Furthermore, bariatric surgery patients had significant risk reductions for developing cardiovascular, cancer, endocrine, infectious, psychiatric, and mental disorders compared with controls, with the exception of hematologic (no difference) and digestive diseases (increased rates in the bariatric cohort). The mortality rate in the bariatric surgery cohort was $0.68 \%$ compared with $6.17 \%$ in controls (relative risk 0.11 , 95\% confidence interval 0.04-0.27), which translates to a reduction in the relative risk of death by $89 \%$.

Obesity surgery, however does not only affect weight. Some studies have made effort to demonstrate post operatives changes in aspects of the psychology of the patient such as quality of life, psychological morbidity and eating behaviour. In terms of health status and quality of life, especially in the patients who have achieved a sustain weight loss. The Cross sectional study John Boan et alt. (2004) reported improvements in weight related quality of life and physical activity. Important as well is 
the work of Jorn Karlsoon et alt. (1998), who reported in a follow up study improvements in the health related quality of life operationalised in terms of mood disorders, mental well-being, health perceptions and social interaction. In terms of impact of surgery on aspects of eating behaviour, the empirical research points into a positive direction. Some studies show how post surgery patients decrease their hunger (Lang et alt., 2002), binge eating (Boan et alt., 2004) and external eating and flexible control (Lang et alt. 2002)

In order to be qualified as a candidate for bariatric surgery, the patient must be 'morbidly obese', which means patients with a BMI $>40 \mathrm{~kg} / \mathrm{m} 2$. Alternatively, patients with a BMI between $35-40 \mathrm{~kg} / \mathrm{m} 2$ with severe comorbidities associated. Finally, patients with a BMI>30 Kg/m2 with associated pathologies that require important eating habits modifications (Chronic Renal insufficiency, Renal, Hepatic or Cardiac transplant). A second array of considerations are taken into account and these include:

- Have participated repeatedly in medically-supervised attempts at weight management without maintenance of weight loss.

- Demonstrate commitment to comprehensive medical and psychological evaluation before and after the surgery.

- Agree to avoid pregnancy for at least one year after bariatric surgery.

- Be capable of and willing to adhere to postoperative nutritional guidelines and exercise program.

- Provide informed consent to surgery.

The guidelines for the implementation of bariatric surgery are recapitulated in a protocol elaborated by endocrinologists, dieticians, gastric surgeons, psychiatrists, pneumologists and anaesthetists.

\section{Enacting the 'bariatric user': from restoration to configuration}

Agnes is 52 years old and she has a BMI of 42 with severe arterial hypertension and the Obstructive Sleep Apnoea Syndrome under control. Joseph is 25 years old and his BMI reaches $46 \mathrm{~kg} / \mathrm{m} 2$ without any related comorbidity. These were the first two patients today in the welcome visit within the protocol. The endocrinologist repeated several times during the session that there is a long waiting list and this week surgeons are beginning to operate patients of 2003. I was curios which patient will go first and I asked the doctor. He explained me that they have to make a selection depending on patient's attachment to the protocol. Sometimes was not purely the order of arrival and they have to see if the surgery is appropriate for the patient. We try to find out if the surgery will be worthy for a particular patient because there are many others waiting for the same opportunity.

Waiting lists are present in a variety of situations and they are operated by public health centres to handle the access to healthcare services. Problems with large waiting lists and long waiting times affect in Catalonia all public hospitals and, more predominantly, those who are located near Barcelona. Since the first bariatric surgical intervention was performed in 1985 at Bellvitge Hospital in Barcelona, a lot has changed. In 2002, 503 bariatric operations were undertaken: 226 by in 10 public hospitals and 277 by 7 private hospitals. The social demand of bariatric surgery has abruptly increased during the last 5 years and today $0,5 \%$ of the Catalan population is afflicted by morbid 
obesity (30.000 patients). This is thought to be the cause of the fact that, in some Catalan hospitals, the time waiting for bariatric surgery is about 3 years.

As Catherine Pope (1991) indicates, waiting lists are more than list of patients waiting their turn to receive treatment. Sometimes, they are used as an account to justify certain health policies that have they produced. They are instrumentals to response to the 'social pressure' to be seen as to be 'doing something' to improve the health system. When policy makers reduce waiting lists, they are working for the sake of the citizenship. The other side of the story are what Pope calls 'individual theories' that blame the actors caught up in the waiting list: patients, doctors and managers. Patients are blamed by messing up the queue for the surgery, cancel at short notice an appointment with the doctor or abuse the system. Doctors are blamed to favour none 'urgent' clinical cases and to ask for unnecessary diagnose tests (X-ray, blood analysis, scanners...). Managers are blamed to fail in conciliating health care needs and economic principles of efficiency.

It has been also argued that in the absence of a market system waiting lists are used to ration scarce resources. Hospitals have been constrained by the government and rationing processes that operate via financial limits (availability of operation theatres, qualified personnel...). Spending in healthcare is not adequate to the social demand: waiting lists arise.

As Pope (1991) points out, waiting lists are located at the base of the organisation, where the supplier meets the costumer. They are collectively administered by trained professionals as well as health professionals. They are a record of all the patients who have been referred for surgery, containing details of the proposed surgery, biographical data and the date of the referral. In the conventionality of the hospital, it is assumed that waiting for admission to the hospital is organised on a 'first comes, first served' basis. Patients' details are kept on a chronological order waiting for their turn. But this does not mean that the earlier you arrive to the surgeon, the earlier you are operated. Tacit functioning of waiting lists show that both patients and doctors favoured dynamics of privilege creating distinctions between those who are able to jump the queue and those who wait their turn. Patient's knowledge, internal relations of friendship, the use of private health... among others are explicative factors of access inequality.

Doctors have a great power over the waiting lists because they are their property and have the ownership wrights. As such, they obtain benefits from them and they move patients in the way they consider more appropriate. Waiting lists provide the opportunity for doctors to deal with patients that obtain personally and professionally more satisfying work. A waiting list is essential to respond to technical advances of medicine and the new fashions in the treatments they can offer.

Today there is an international course on bariatric surgery in the hospital and I have been invited to assist. One of the best bariatrical surgeons, Dr. Figueroa, will teach in a live sessions how to operate laparoscopically a gastric by-pass with mechanical anostomosis. Instead, as a condition for this operation, Dr. Figueroa wanted to incorporate an adjustable gastric band (AGB) to masculine patient with a BMI of 50 and with a binge eating disorder. Days after, one surgeon explained me how difficult the organisation of the course was. They couldn't find a patient for the AGB. Fortunately, Lucy, the admissions manager, could find the AGB profile of a patient who entered in the waiting list two months ago. The surgeon acknowledged that this situation wasn't fair, but he was captured by those who have the most advanced techniques.

With this example, my intention is not overemphasize the power of doctors over the waiting lists. Doctors are bounded by protocols and major regulations. Procedures which routinely help them to 
cope with the complexity of the waiting lists: the first to arrive to the hospital might not be the first patient who needs bariatric surgery. This is precisely the second framework in which my ethnography is taking place. As an official unit which surgically treats morbid obesity, the hospital is legally required to apply a protocol which includes fairness in the access to the treatment.

According to Mark Berg (1998) protocols go beyond its nature of preformed recommendations issued for the purpose of decision-making in medical practice. They might help the health professional by analysing decisions before the fact and prevent the mental paralysis and chaos. They have also a normative dimension as the protocol ensures that the actions and interpretations of actions will have the same outcomes in any participating professional. They describe the good clinical reason in a way that becomes transferable, evaluable and scientific. In is the device by which order is brought into medical practice, which includes different professionals. Protocols integrate different medical specializations around the same 'object'-morbid obesity.

The implementation of a protocol is not simply a question of homogenizing medical practice by replacing "messiness with the orderliness of a 'good' medical practice X. [...] A protocol is not an inert tool: its specific, formal structure transforms the order it transport in distinctive ways" (Berg, 1998: 228). This transformation affects both medical practice as well as patients. And this is precisely what changes: before becoming a patient, you are candidate.

\section{Therapeutic contract}

Family Name and Name

Identity Card Number.

Following the indications of my doctor, I acknowledge that

- I am informed about that fact that Obesity is a chronic disease that favours the appearance of related pathologies such as hypertension, diabetes mellitus, breathing problems mobility problems and so on.

- I know that the treatment requires following strict rules of nutrition and physical exercise prescribed by the medical team

- I accept the commitment to loose the weight that the medical team considers appropriate to my specific condition and /or situation.

- I am informed about the obligation of following the prescribed medical controls.

- The lack of commitment and non following the prescribed rules may result in the exclusion as a candidate to be operated in the protocol of bariatric surgery.

Date

The patient

The Doctor 
It is Wednesday 15: $00 \mathrm{pm}$ and I arrived a little bit late but the endocrinologist hasn't begun with the first patient yet. I entered in the desk and I taked a chair. Dr Perez calls the first patient and a Judith goes in. She starts to explain that is 45 years old and wants to solve her problems with weight. Dr. Perez calculates her BMI. It is $45 \mathrm{~kg} / \mathrm{m} 2$ and matches one of the eligibility criteria. He also asks if she has any obesity health related problem. She answers that arterial hypertension and knee pain (though she is not sure that if it's due to morbid obesity). Dr Pérez nods and he gives to understand that Judith meets the physical requirements to be treated in the hospital. He explains that today he is not going to give her anything to do. First doctors want to know her a little bit, especially in the areas of eating habits and physical exercise. Dr Pérez also gives her a therapeutic contract so Judith signs it. Dr. Perez justifies it by saying that they have seen patients that have not done enough for the surgery. Once they are operated they go back to previous lifestyle and in the best cases, regain weigh. Sometimes, they have to be re operated because the pouch brakes because they eat food that his new digestive system is not prepared to process.

The fragment above contains detailed criteria to be candidate as a precondition for becoming a bariatric patient. A BMI above $40 \mathrm{~kg} / \mathrm{m} 2$ is only of the eligibility criteria to begin with the long trajectory to be include in the waiting list for bariatric surgery, waiting list in the hands of the surgeon who will operate the patient. Thus, protocols become a concatenation of obligatory points of passage for the candidate, for its body and for its morbid obesity.

Protocols and waiting lists are two forms of dealing want we know as the "problem of diversity". By enacting a typical patient trajectory, medical practice does not simply restore from illness to healthiness. Bariatric surgery selects its candidates:

I was with Iñaki, a dietician that recently has started to work in the unit. Today we have been receiving patients that are still not operated but following a diet prescription prior to visit the surgeon. I was amazed how clear the boundary between allowed and prohibited food. So I asked him what would happen if a patient, who was vegetarian and, due to a thyroid disorder, applied for bariatric surgery because he is morbid obese. Iñaki took some seconds and asked me that this kind of surgery wasn't for him. Operated patients have to eat a lot of meat and fish because they will experience difficulties in absorbing proteins. Their new digestive system passes by the area of small intestine where we normally absorb proteins.

And selecting the candidate means preparing the candidate for the surgical operation, to the new digestive system and new life-style (eating habits and physical exercise). Following Steve Woolgar (1991), the implementation of a bariatric surgical technique includes configuring the user of such technique: defining, enabling and constraining. Bariatric surgery calls for a psychological preparation on the part of the patient and a fairly long period of adaptation to life with a small stomach and malabsorptive intestines. It compels patients to change their eating habits radically, and makes them very ill if they overeat. And after bariatric surgery is performed, patients remain at a lifelong risk of nutritional deficiencies. The higher the motivation of patients to lose weight, and manage the postoperative requirements of dietary modification and behavioural therapy, the more successful Bariatric surgery is likely to be, in solving their obesity and weight problems. The success of the bariatric surgical technique not only depends on the technique itself.

I carried on drinking a quarter of litre of water and a quarter of a litre of peach juice every 24 hours. What happened was that my ability to smell highly developed and I could smell what was prepared in the kitchen: today fish or omelette... Well, I knew that this wasn't for me but for other patients. For me, 
it was enough with water and juice. I took a decision and cross the border and now I had to work hard to keep what was done within the operation room. I didn't want to eat again for the rest of my life, because surgery only does the $50 \%$ and the other half depends on you, yourself. You know... exercise and new eating habits. (Mary, 1234)

The success of the technique depends on the mutual shape of the technique itself and its context of use. "The capacity and boundedness of the machine [technique] take their sense and meaning from the capacity and boundedness of the user" (Woolgar, 1991: 68). In configuring candidates as users, the protocol is establishing the parameters of their future actions. This means managing waiting lists and selecting the candidates that better shape the requirements of the 'new digestive system'.

I didn't understand why pre-op patients are dieting if they have not visit the surgeon. I asked Iñaki and I couldn't expect the answer: It is a rehearsal for the surgery. We trained them in the eating habits they will have as a post-op patient. We are conscious that is not easy to understand for the patient that he/she will not be able to eat more that a 40 grams of bread. It is not easy as well to avoid drinking before eating [If they do so, the pouch there is no place for food]. They need some time to do... you know this click! Change their mind.

Before the candidate meets a surgeon, he must be a user as well. This is accomplished by relying on "usability trials". "Even if a technology is a black box, such as a home stereo system, the user still has to know how to switch on the amplifier, how to connect the wires correctly, and under which conditions the machine can be used and so on. In general, the more the technology depends on the concern actions of human users for its successful operation, the more it will need to be tested in vivo" (Woolgar, 1991: 35-36).

If we follow the protocol, when the patient leaves the welcome visit he will be assigned to a dietician who will be following the case individually for a period of nine months. The dietician will assess and monitor changes in the eating habits of the candidate according to the requirements of the surgical technique. In the meantime, the candidate will be seeing an endocrinologist as well.

The pre-op usability trial has two differentiated processes at work. The first tries to converge the trajectory of the candidate to the trajectory of the ideal user. The second morally entitles the candidate with the label of user when the two trajectories melt.

Converging trajectories implies making certain aspects present and certain aspects absent. It implies establishing preconditions for the surgery that become points of obligatory passage before visiting the surgeon and joining his waiting list. These give shape to the user of bariatric surgery and include:

\section{Clinical History:}

To consider risk factors in association with arterial hypertension, diabetes mellitus, dyslipidaemia, smoking habits, hyperuricemia, etc.

\section{Dietetic History:}

To review patient's eating biography, eating patterns, amount of food consumption, sweet and alcoholic drinks.

\section{Eating habits and self-care:}

Frequency and time distribution of meals, grazing habits, eating at night, binge eating under an 
episode of stress

\section{Physical Exercise:}

To capture the amount of physical activity during working time, in leisure time both daily and weekly.

Fami8liar and Social environment:

To understand psychiatric influences and familiar support

\section{Physical examination:}

BMI calculation, waist and hip perimeter, arterial pressure.

The head of endocrinology reviews the general evolution of the patient during the last 9 months. He pays attention to the changes in the body weight and the evolution of the BMI. If the tendency has been a decline, this means that the candidate has been adhered to the dieting rules. He, then, [moral entitlement] deserves bariatric surgery:

If you see they have lost at least $10 \%$ of their initial weigh during this nine months, this means that they that they have been working hard. It is not easy to loose 15 kilos for someone who weights 130 kilos. This means that they are personally coherent enough to know what bariatric surgery is and what consequences for their life the operation will have. On the contrary is also true. If the candidate hasn't lost enough weight, the body doesn't lie. We are operating digestive systems and that's why we include psychiatric evaluation prior to surgery.

Once the candidate has the approval on the five dimensions the protocol requires, the head endocrinologist of the unit sends him to the surgeon. The surgeon will then evaluate if the weight loss is enough or the patient has to go back to the dietician:

In this kind of invasive operations imply a high risk for the patient. We have to take this into account and see if the patient consciously knows about this. If you allow a candidate to visit the surgeon with the same BMI as in the beginning, you are harming other candidates that are also working hard. We have to prepare the body for the surgery. If the patient doesn't reduce weight [15 kilos at least], this means concentration of fat in the stomach as well as in the liver. The surgeon will not use laparoscopy because the liver is too large for the camera to see with enough clarity. Also throcars can't be fixed in patient's abdomen and staplers are not long enough to arrive to the stomach. You know, with a laparotomy the risk for the patient increases and post-op recovery is longer and more painful.

The decrease of the BMI is in the hands of endocrinology synonym of personal coherence, a guarantee of patient's autonomy and of the ability to cope with the post-op eating habits. At the same time, the BMI determinates for the surgeon the kind of operation the patient will receive. In other terms, he sees BMI in terms of risk in the operation theatre. With a laparotomy, the risk for the patient is higher than a laparoscopy. Consequently, the surgeon prefers to send the patient back to the label of candidate (eating habits modification by medical supervised dieting) than to face any unpredictable complication during the operation.

However, the responsibility of patient's risk within the operation theatre has a second obligatory point of passage: the arterial gasometry test. The pressure of oxygen in blood (O2P) for a non morbid 
obese patient is about $75 \%$. Anaesthetists reject any patient with an $\mathrm{O} 2 \mathrm{P}$ below this percentage. This measure of 'normality' doesn't seem to be applicable to morbid obese patients who, due to their extreme weight, have lungs capacities diminished.

"Sometimes driving a patient to the operation theatre is very hard. As endocrinologists, we are constantly fighting with anaesthetists, who can't understand that the pattern of normality they have for normal patients doesn't fit the nature of lungs ability to generate oxygen. I have discussed many times with our pneumologist and we fully agree that our patients can't reach an O2P above $65 \%$. How can we explain this to the patient succeed in weight loss and has been waiting for the operation at least two years?

As soon as this percentage is increased by administering a CPAP treatment (Continuous Positive Airway Pressure), the patient goes into the operation theatre. Bearing in mind the work of Tiago Moreira (2004), which accounts for the coordination in the operation room, a new life begins (Jane, 0248)

\section{Keeping bariatric surgery 'alive': preventive care as body configuration.}

After having gone through the surgery, patients are implicated in various types of medical recommendations aimed at adjusting their bodies and selves to operative social and material environments. As Moreira (2004) explains, the process of detachment as a shift in the conditions for recognition of self-in-action organised by the social, medical and technical elements constructed in the surgical wards and the various laboratories of the hospital (Moreira, 2004: 33). Depending on this detachment, bariatric surgery will have a greater of lesser impact on body patient's weight.

\section{Dr. Ruiz tells to patient operated yesterday:}

We want you to have excellent results from your surgery. We will help you to achieve your goal of better health and quality of life through significant weight reduction. You have to take an active part in your recovery and be committed to the follow-up, at least on an annual basis, all of your life. All successful patients who have had the gastric bypass have 2 things in common: they follow their dietary recommendations closely, and they initiate a regular exercise program.

The patient spends three days of post-operative recovery in the hospital depending on the nature of the surgery. Immediately after the surgery, they will receive fluids through a needle into a vein (intravenous). The morning after your surgery, the patient will start on small amounts of clear fluids and the intravenous fluids will be stopped by that evening. A recommended diet will begin while in hospital and will be asked to continue this diet at home. The return to eating solid food after the operation will be gradual. These are the maximum quantities of food recommended

\begin{tabular}{|l|l|l|l|l|}
\hline MEAL & $\begin{array}{l}\text { Day 1 After } \\
\text { Operation }\end{array}$ & $\begin{array}{l}\text { Days 2 \& 3 After } \\
\text { Operation }\end{array}$ & Days 4 \& 5 After Operation \\
\hline BREAKFAST & $1 / 4$ cup apple juice & $1 / 4$ cup cream of & $1 / 4$ cup cream of wheat or \\
\hline
\end{tabular}




\begin{tabular}{|c|c|c|c|}
\hline & 1/4 cup Jello & $\begin{array}{l}\text { wheat } \\
1 / 4 \text { cup } 2 \% \text { milk } \\
\text { (regular or Lactaid) }\end{array}$ & $\begin{array}{l}\text { oatmeal } \\
\text { 1/4 cup } 2 \% \text { milk (regular or } \\
\text { Lactaid) }\end{array}$ \\
\hline $\begin{array}{l}\text { MORNING } \\
\text { SNACK }\end{array}$ & 1/2 cup apple juice & $\begin{array}{l}\text { 1/4 cup low fat yoghurt } \\
1 / 4 \text { cup pureed fruit }\end{array}$ & $\begin{array}{l}1 / 4 \text { cup low fat yoghurt } \\
1 / 4 \text { cup pureed fruit }\end{array}$ \\
\hline LUNCH & $\begin{array}{l}\text { 1/4 cup } \\
\text { Consommé } \\
1 / 4 \text { cup Jello or } \\
\text { grape juice }\end{array}$ & $\begin{array}{l}\text { 1/4 cup cream soup } \\
\text { 1/4 cup pureed fruit }\end{array}$ & $\begin{array}{l}1 / 4 \text { cup cream soup } \\
1 / 4 \text { pureed fruit }\end{array}$ \\
\hline $\begin{array}{l}\text { AFTERNOON } \\
\text { SNACK }\end{array}$ & 1/2 cup apple juice & $1 / 2$ cup pureed fruit & $1 / 2$ cup pureed fruit \\
\hline SUPPER & $\begin{array}{l}\text { 1/4 cup Chicken } \\
\text { broth } \\
\text { 1/4 cup Jello or } \\
\text { grape juice }\end{array}$ & $\begin{array}{l}\text { 1/4 cup cream soup } \\
\text { 1/4 cup applesauce }\end{array}$ & $\begin{array}{l}1 / 4 \text { cup cream soup } \\
1 / 4 \text { cup low fat yoghurt }\end{array}$ \\
\hline $\begin{array}{l}\text { EVENING } \\
\text { SNACK }\end{array}$ & 1/2 cup apple juice & $\begin{array}{l}1 / 2 \text { cup } 2 \% \text { milk } \\
\text { (regular or Lactaid) }\end{array}$ & $\begin{array}{l}1 / 2 \text { cup Carnation Instant } \\
\text { Breakfast or milkshake }\end{array}$ \\
\hline
\end{tabular}

Doctors do not expect the patient to consume everything - each individual will be different. It is important not to take more than $15-30 \mathrm{~mL}$ ( $3-6$ teaspoons) at a time. Sipping on fluids continuously will help to prevent dehydration. Carbonated soft drinks (with bubbles) may cause abdominal distention and are not recommended.

When the patient leaves the hospital, the process of detachment follows by learning how to eat during the period of major weight loss. Though the bariatric surgery is not reversible, its effectiveness (in terms of weight loss) is concentrated after the 18 months following the operation. During this period is when the patient has to "work harder":

Dr. Ruiz tells to a patient in the first meeting after the surgery:

The modifications made to your gastrointestinal tract will require permanent changes in your eating habits that must be adhered to for successful weight loss. There are 7 cardinal rules that you must follow in order to attain a weight that is close to your ideal body weight:

1. Meals larger than 1 cup may result in weight gain.

2. Consumption of an adequate amount of liquid, preferably water, is crucial. Patients should consume a minimum of 1 1/2-2 litres of liquid per day. This should be done slowly and throughout the day. Never drink more than 2 oz. of liquid in a 10-15 minute period. To prevent dehydration, this amount should be increased by $10-20 \%$ when the weather is very hot and humid. 
3. You should have 3 regular meals and 3 small snacks per day (see Seven-day menu). "Grazing" on small amounts of food throughout the day will sabotage your weight loss and result in the inability to lose an adequate amount of weight.

4. The primary source of your nutrition should be protein. 20 to $25 \%$ of all calories consumed should be protein-based (eggs, fish, meat, etc.). Carbohydrates (bread, potatoes, etc.) should make up only about 10\%-20\%, and fats (butter, cheese, etc.) only 5\%-15\% of the calories that you eat. A diet consisting of 1200 calories and about 70 grams of protein should be your goal. Hair loss, cracked nails, and defective healing and immunity are just some of the side effects of inadequate protein consumption (not to mention difficulty losing weight).

5. Never drink liquids when eating solid foods. Liquids should be avoided for a period of 30 minutes before and 60 minutes after eating solid food or meals.

6. Avoid foods which contain sugar. Not only will they slow your weight loss, but they will make you sick! Sugar causes "dumping" in patients who have had the gastric bypass procedure. Dumping Syndrome occurs when sugars go directly from you stomach to your small intestine, causing heart palpitations, nausea, sweating, abdominal pain, and diarrhoea. Dumping Syndrome occurs also when food is "dumped" too rapidly in the small intestine.

7. Stop eating or drinking when you begin to feel full. "Stuffing yourself" may cause your stomach pouch to stretch - or worse, burst - causing long-term problems and complications.

By these general guidelines, the patient is learning to eat again and the link between the surgeon and the patient is being undone. The patient is gaining self-control over the way to eat and the way to manipulate the body: he will be actively losing weight. In medical a medical terminology, this process can be associated with the category of 'recovery'. Within the medical world, morbid obesity is treated as a naturally given disease and malleable discrete entity at various levels of scale: metabolic (drug treatments), physical (exercise and diet) and psychological (behaviour modification therapy). The epistemological requirements of scientific medicine carry with them a commitment to the idea of human body as a coherent, naturally given biological fact. This enacts a simple definition of treatment. For example, bariatric surgery is defined as the tool/process in charge of curing morbid obesity as pathology. In this sense, treatments produce good health.

Following this pathology-treatment simplified relationship, we might be tempted to think that "good health" is narrowly related to the transition from the clinical condition of 'morbid obesity' to the clinical definition of 'severe obesity' according to the Body Mass Index of the person afflicted. At macro-level it seems that this person is "cured", but this state of being cured it is a state that at micro practices is turbulent and unclear, multiple and fragmented. Surgery, as one of my interviewees explained to me, "only does the $50 \%$ ":

I carried on drinking a quarter of litre of water and a quarter of a litre of peach juice every 24 hours. What happened was that my ability to smell highly developed and I could smell what was prepared in the kitchen: today fish or omelette... Well, I knew that this wasn't for me but for other patients. For me, was enough with water and juice. I took a decision and cross the border and now I had to work hard to keep what was done within the operation room. I didn't want to eat again for the rest of my life, because surgery only does the $50 \%$ and the other half depends on you, yourself. You know... exercise and new eating habits.

The specificity of patient's "shifting out" in bariatric surgery relies upon an organic ontological displacement (Bloomfield \& Vurdubakis, 1999). This is to say that process of patient's detachment from the hospital depends on the conditions of possibility and impossibility that the new digestive systems is able to enact in daily life. In other words, emerging dispositions of agency will depend on the mediation of the patient's digestive system. The new digestive system becomes, in this way, a 
generative node that allows certain set of relationships but discard many others. In order to be a 'healthy', digestive incoherences have to be made absent by providing the consciously balanced amount of food assumable by the post-operative digestive system. And this makes difference between having a surgery and living with a surgery:

I give myself 300 calories per day of chocolate (because I can't live without it) and I try to always think before I put anything in my mouth. If I don't love it, than I don't waste my calories on it. The biggest lesson I have learned is "you do not have to finish it." What works for me is small portions. I have anything and I mean anything, but only a little bit. I think each person has to find the method that will work for them. It has taken me 46 years and major surgery, but I think I have finally found my personal method. I eat about 8 times per day but only about 150 - 300 calories each time. Sometimes it is protein, sometimes fruit, sometimes pretzels, sometimes veggies, sometimes a muffin, sometimes chocolate.

The bariatric digestive system becomes in this sense unpredictable, a fluid that always escape creating contours of elusiveness. The digestive process might collude with the set of relations in which it is being enacted.

For instance, when the bariatric surgery is enacted in relation to pregnancy. Within this period, the materiality of food required for double feeding (mother and phoetus) and the digestive system of the pregnant women do not fit together. The pouch that results of the bariatric surgery is not initially prepared to absorb the amount of food involved. This means that the pouch, as fluid object, will adapt to the present state and will itself enlarge:

I had gastric bypass in 1989 at 155 kilos. I lost down to 88 kilos then regained to about 90 kilos. I held at 100 kilos for 9 years until 1998 when I got pregnant and had my son. During pregnancy I gained to 127. After I got back down to 113 kilos but I noticed I could eat anything I wanted with no limit. It was like the surgery were off or my stomach stretched after back trouble and steroid injections I again ballooned to 130 kilos.

A second illustrative example can be found when the bariatric digestive system is at work in liaison with a context of care taking. The materiality of food becomes a mean to carry on with the difficult task and effort of taking care of an ill person. Caring related tasks are just one of the aspects of domestic labour and, going along with it, there tasks of cleaning, cooking and so on. Within the life of a post operated, the materiality of chocolate becomes a little pleasure by which she obtains energy to carry on working and coping with mundane troubles:

Everything changed when my husband felt ill and I had to take care of him. Along with this situation, I had lots of problems with my daughter. The fact was that I started to eat chocolate unconsciously.... Well, not exactly! I would say consciously... Yes, yes... consciously!! Chocolate gave me strength to cope with my troubles in my daily life. The problem came when one day I decided to weigh my self again and I saw that .... I had gained 22 kilos!! It was terrible because I felt strongly bad with my self because I crossed the border back again!. I started to wonder what happened this to me ...Why me?

A third example is in relation to the bariatric digestive in a work related context. Compliance with the post-surgical dietary guidelines may not always be easy. The first few months are a time of adjustment. When a regular diet resumes, some patients experience what is known as "dumping syndrome." This condition occurs when large amounts of high-calorie foods, especially those containing sugar, pass quickly from the stomach pouch into the intestine. Fluid rushes into the small 
intestine to dilute the high concentration of sugar. The patient may feel faint, break out in a cold sweat, and have intestinal cramps followed by diarrhoea. Fortunately, "dumping syndrome" can usually be averted simply by avoiding high intakes of sweets.

Jane came today to see urgently the endocrinologist. She was operated five years ago and her body weight has been stabilised. She experienced the so called "dumping syndrome" the first year after the operations. As she says, she wasn't an expert user. At the same time, as an associated phenomenon, she experienced continuous diarrhoea. She used to go to the toilet at least 10 times a day. She couldn't control the moment to go to the toilet. Though the dumping syndrome disappeared with eating guidelines, the diarrhoea diminished only in frequency. She learned to live going 4 times a day to the toilet. She was working in a bar and the toilet wasn't far away. However, today she has a car parking job in a hotel. There is no toilet near by, and her boss doesn't want to take any responsibility!

Such contours might collude with one of the preconditions by which all the surgical process began: the restitution of autonomy to a morbid obese patient. "By ordering patients in terms of their openness, nurses and other professionals articulate the patient to the possibility of becoming personified again. This is because patients arrive at the wards from the operating room lacking the main characteristics of personhood as it is defined on the neurosurgical wards: autonomy. Re-personification, corresponds, thus, to the public recognition of patient's ability to take care of him/her self and to a re-integration in the social and material world." (Moreira, 2004: 40).

With this purpose, is when the notion of detachment takes in medical practice the form of a "preventive care": in order to arrange and create links and connections between the new digestive system and those entities which contribute to the obduracy of the "normal body" though having intended disfuncionalities at work. These attempts allows the surgery be kept as a whole, in terms of maintained weight lost and patient's personal autonomy.

In a leaflet for patients' information:

We want you to have excellent results from your surgery. We will help you to achieve your goal of better health and quality of life through significant weight reduction. You have to take an active part in your recovery and be committed to the follow-up, at least on an annual basis, all of your life.

In relation to the extract above becomes useful Ingunn Moser and John Law (1999) designate as the "theory of normalisation". Preventive care for bariatric surgery relies on a systematic work to allow the patients to regain or develop their ability to function and master their lives, with the endeavour of giving them the highest degree of independence and quality of life. This is to say the patient as "identical to what we have learned to call 'the modern, liberal, subject': the independent, autonomous, centred, singular verbal and therefore competent subject (Moser, 2000: 209).

Finally, preventive care implemented becomes highly asymmetrical. Asymmetrical because only incorporates a mode of digestive system. Preventive care takes the assumption on the body as a discrete and bounded unit. Equally, bowels mal absorptive properties and reduced stomach are contained within this body and affect it in different ways. And this body with its bariatric digestive system belongs to a individual, who is responsible of it

\section{Dr. Ruiz explains:}

Patients have got the surgical tool to control your hunger, now add the behavioural tools, so their procedure can help them to its maximum effect. There are other side effects associated with gastric 
bypass. Some people find they can no longer tolerate lactose-containing products. Hair loss is another consequence, as the body adapts to having a sudden reduction in calories and protein. Patients will need to take nutritional supplements to make up for certain vitamin deficiencies related to the surgery. Specifically, food now bypasses the duodenum, where iron and calcium primarily are absorbed. Without sufficient iron, anaemia can develop, and when there is not enough calcium intake, osteoporosis and metabolic bone disease can occur. That is why it is important for patients to take the nutritional supplements as directed by their doctor.

Because of the limitation of food intake imposed by the surgery, you will not be able to take in all the required vitamins and minerals - so vitamin supplementation is important. The following should be taken every day for the rest of your life:

1. Multivitamins such as Hidropolivit 1 per day. Twice a day if it is a children chewable vitamin, once a day if it is an adult chewable vitamin.

2. Calcium - 500 mg twice a day. Most patients prefer Osteomerk D because it tastes good and is easy to take. 1 Tums every day is also a good source.

3. Vitamin B12 - 250 micrograms per day.

4. Palafer $300 \mathrm{mg}$ po once per day for menstruating women.

Vitamin deficiencies such as vitamin B12 can lead to paralysis if not detected and treated, so your post-operative follow-ups are extremely important. Basically, you will be with us for the rest of your long and happy life after the surgery.

But what happens when if the body is not bounded and bariatric digestive is in itself relational and distributed? How is preventive care prevented from this possible scenarios? For example in relation to pregnancy, care taking or work?

\section{Concluding remarks}

In this article we have focussed on the notion of configuration to argue that bariatric surgery is not simply a process of restoration from illness to healthiness. On the one hand, bariatric surgery configures candidates for its success. On the other hand, it results in a generative digestive system which enacts organic body displacements rather than medical "side effects"

In the framework of waiting lists and medical protocols, this kind of surgery copes with the issue of patient's diversity by making a selection. Not all obese body arriving are the hospital are potentially operable. Only those who potentially follow certain concatenations of obligatory points of passage (reducing weight before the surgery, eating low energy food...). The configuration process finishes when the obese body becomes a candidate, when all the usability trials are favourable and prognosticate a success of the surgery within and after the operation theatre.

Once the patient is operated a new digestive system is created. Medical professionals are keen on detailing a wide range of possible side effects related with stomach reduction and mal absorptive properties. However, the new digestive system becomes a generative node that allows certain set of relationships but discard many others. In order to be a 'healthy', digestive incoherences have to be made absent by providing the consciously balanced amount of food assumable by the post-operative 
digestive system. And this makes difference between having a surgery and living with a surgery. The bariatric digestive system becomes in this sense unpredictable, a fluid that always escape creating contours of elusiveness (pregnancy, domestic labour...). The digestive process might collude with the set of relations in which it is being enacted. And, specifically, with one of the preconditions by which all the surgical process began: the restitution of autonomy to a morbid obese patient.

With this purpose, is when the notion of detachment takes in medical practice the form of a "preventive care": in order to arrange and create links and connections between the new digestive system and those entities which contribute to the obduracy of the "normal body" though having intended disfuncionalities at work. These attempts allows the surgery be kept as a whole, in terms of maintained weight lost and patient's personal autonomy.

In relation to the extract above what becomes useful Moser and Law (1999) designate as the "theory of normalisation". Preventive care for bariatric surgery relies on a systematic work to allow the patients to regain or develop their ability to function and master their lives, with the endeavour of giving them the highest degree of independence and quality of life. This is to say the patient as "identical to what we have learned to call 'the modern, liberal, subject': the independent, autonomous, centred, singular verbal and therefore competent subject (Moser, 2000: 209)

Finally, preventive care implemented becomes highly asymmetrical. Asymmetrical because only incorporates a mode of digestive system. Preventive care is based in the assumption on a body that is discrete and bounded. Equally, bowel mal absorptive properties and a reduced stomach are contained within this body and affect it in multiple ways beyond the control of the patient. However, this body with its bariatric digestive system belongs to an individual, who is responsible of it.

\section{References}

Berg, Mark. (1998). Order(s) and disorder(s): of protocols and medical practices. In Mol, A.M. and Berg, M. (eds.), Differences in Medicine: Unravelling Practices, Techniques and Bodies. (pp. 226-238). London: Duke University.

Bloomfield, Bryan and Vurdubakis, Theo. (1999).The Outer Limits: Monsters Actors Networks and the Writing of displacement. Organization, 6 (4), 625-647.

Boan, John.; Kolotkin, Ralf.; Westman, Eric; McMahon, Robert and Grant, John. (2004). Binge eating, quality of life and physical activity improve after Roux-en-Y gastric bypass for morbid obesity. Obesity Surgery, 14 (3), 341-348.

Christou, Nicolas.; Sampalis, John.; Liberman, Moishe.; Look, Didier.; Auger, Stephan.; McLean, Alexander and MacLean, Lloyd. (2004). Surgery decreases long-term mortality, morbidity, and health care use in morbidly obese patients, Annals of Surgery, 240 (3), 416-23.

Karlsson, Jorn.; Sjostrom, Lars and Sullivan, Marianne. (1998). Swedish Obesity Study (SOS) - and intervention study of obesity. Two year follow up of health related quality of life (HRQL) and eating behaviour after gastric surgery for severe obesity. International Journal of Obesity, 22, 113-126. 
Lang, Theo.; Hauser, Ralph.; Buddeberg, Catherine and Klaghofer, Rudolph. (2002). The impact of gastric banding on eating behaviour and weight. Obesity Surgery, 12, 100-107.

Galibert, Laurent and Kral, Joseph. (2001). Weight Loss Surgery for Obesity. Philadelphia: American College of Physicians.

Moreira, Tiago. (2004). Coordination and Embodiment in the Operating Room, Body and Society, 10 (1), 109-129.

Moser, Ingunn. (2000). Against Normalisation: Subverting Norms of Ability and Disability, Science as culture, 9 (2), 201-240.

Moser, Ingunn and Law, John. (1999). Goog passages, bad passages. In Law, J. and Hassard, J. (eds.). Actor Network Theory and after. Oxford: Blackwell and the Sociological Review.

Ogden, Jane. (2003). The psychology of eating: From healthy to disordered behaviour. Oxford: Blackwell.

Perri, Michael; Nezu, Arthur; McKelvey, Wendy; Shermer, Rebecca and Stephen D. Anton. (2001). Relapse prevention training and problem solving therapy in the long term management of obesity. Journal of Consulting and Clinical Psychology, 69 (4), 722-726

Pope, Catherine. (1991). Trouble in store: some thoughts on the management of waiting lists. Sociology of Health and IIIness, 13 ( 2), 193-212.

Torgerson, Jurgen and Sjostrom, Lars. (2001). The Swedish Obese Subjects (SOS) study - rationale and results. International Journal of Obesity, 25 (1), 134-140.

Wilson, Gillian. (1995). Behavioral treatment of Obesity: Thirty years and counting. Advances in Behavioural Research Therapy, 16, 31-75.

Woolgar, Steve. (1991) Configuring the User. In J. Law. (ed.). A Sociology of Monsters: Essays on Power, Technology and Domination. (pp. 58-100) London: Routledge.

\section{Historia editorial}

Recibido: 09/09/2006

Aceptado: 22/10/2006

\section{Formato de citación}

Sanz Porras, Jordi. (2006). Configuring bariatric bodies: exploring surgery beyond the hospital. Athenea Digital, 10, 103-120. Disponible en http://antalya.uab.es/athenea/num10/sanz.pdf.

Jordi Sanz Porras. (1977, Barcelona). Licenciado en sociología (UAB) y DEA en Psicología social $(\mathrm{UAB})$ 


\section{SOMIERIGHISRESERVED}

Este texto está protegido por una licencia Creative Commons.

Usted es libre de copiar, distribuir y comunicar públicamente la obra bajo las siguientes condiciones:

Reconocimiento: Debe reconocer y citar al autor original.

No comercial. No puede utilizar esta obra para fines comerciales.

Sin obras derivadas. No se puede alterar, transformar, o generar una obra derivada a partir de esta obra.

$\underline{\text { Resumen de licencia }}$

Texto completo de la licencia 